
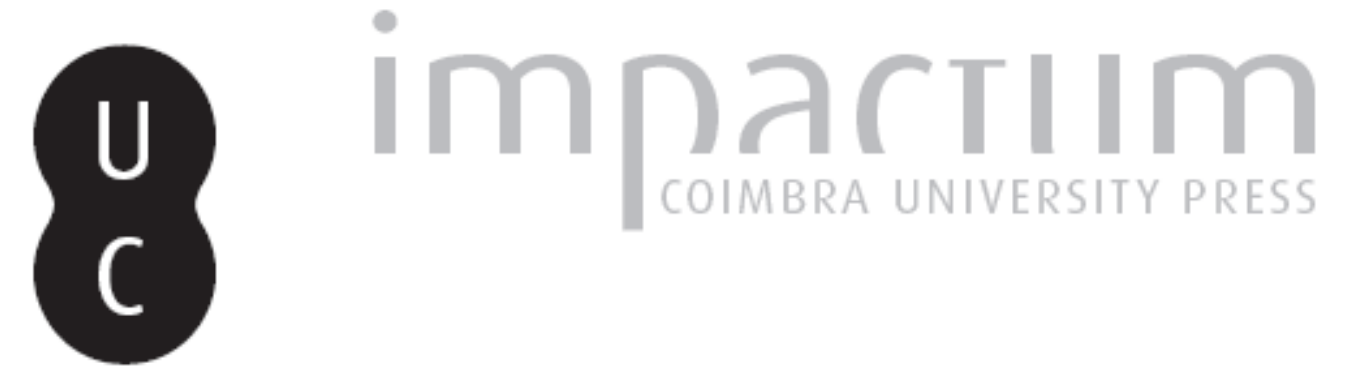

\title{
[Recensão a] Solin (Heikki) e Salomies (Olli), Repertorium Nominum Gentilium et Cognominum Latinorum
}

\author{
Autor(es): D'Encarnação, José
}

Publicado por: Imprensa da Universidade de Coimbra

URL persistente:

URl:http://hdl.handle.net/10316.2/45536

DOI:

DOI:https://dx.doi.org/10.14195/1647-8657_30_14

Accessed : $\quad$ 26-Apr-2023 12:01:01

A navegação consulta e descarregamento dos títulos inseridos nas Bibliotecas Digitais UC Digitalis, UC Pombalina e UC Impactum, pressupõem a aceitação plena e sem reservas dos Termos e Condições de Uso destas Bibliotecas Digitais, disponíveis em https://digitalis.uc.pt/pt-pt/termos.

Conforme exposto nos referidos Termos e Condições de Uso, o descarregamento de títulos de acesso restrito requer uma licença válida de autorização devendo o utilizador aceder ao(s) documento(s) a partir de um endereço de IP da instituição detentora da supramencionada licença.

Ao utilizador é apenas permitido o descarregamento para uso pessoal, pelo que o emprego do(s) título(s) descarregado(s) para outro fim, designadamente comercial, carece de autorização do respetivo autor ou editor da obra.

Na medida em que todas as obras da UC Digitalis se encontram protegidas pelo Código do Direito de Autor e Direitos Conexos e demais legislação aplicável, toda a cópia, parcial ou total, deste documento, nos casos em que é legalmente admitida, deverá conter ou fazer-se acompanhar por este aviso.

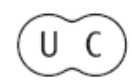


FACULDADE DE LETRAS

INSTITUTO DE ARQUEOLOGIA

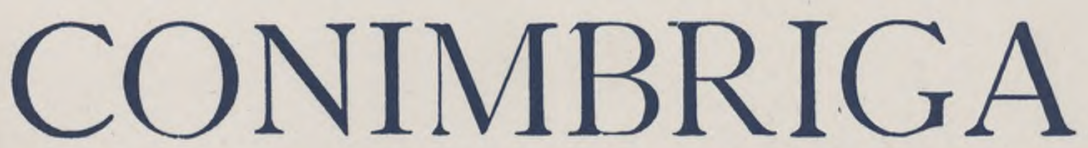

VOLUME XXX

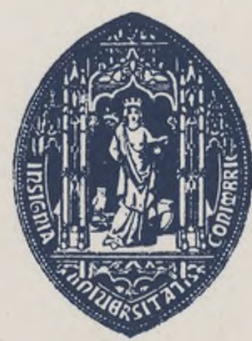

UNIVERSIDADE DE COIMBRA 
perspectivas de trabalho, aproximando-nos da investigação que se realiza além-fronteiras e que tem produzido frutuosos resultados.

Neste contexto, a obra agora editada com o título "Les Villas Romaines de S. Cucufate (Portugal)" representa, não só um pilar para o estudo e compreensão das villae na importante província da Lusitânia, como também uma reflexão aprofundada sobre o fenómeno rural na época romana. Constitui, por isso mesmo, uma referência obrigatória na historiografia arqueológica romana e um modelo para futuros trabalhos neste domínio. Finalmente, este obra reflecte os resultados de um frutuoso trabalho de equipa e, como tal, não pode deixar também de ser olhada como um excelente exemplo para a arqueologia portuguesa que carece em absoluto do benefício da cooperação, eivada que está de individualismo, tão militante, quanto infrutífero.

Bibliografia citada:

Alarcão, Jorge de (1988). Roman Portugal, Warminster, England - (1990). O domínio romano, Portugal das Origens à Romanização (coord, de J. de Alarcão), Nova História de Portugal, Editorial Presença, Lisboa, pp. 345-437.

Nolen, J. U. S. (1988). Vidros de S. Cucufate, Conimbriga, XXVII, pp. 5-59.

Manuela Martins

Solin (Heikki) e Salomies (Olli), Repertorium Nominum Gentilium et Cognominum Latinorum, Olms-Neidmann, Hildesheim —Zurique - Nova Iorque, 1988, 474 pp. ISBN 3487079860.

Quando abre um repertório onomástico, o investigador pretende saber se determinado antropònimo com que deparou já se encontra documentado, se os testemunhos da sua existência são abundantes ou raros; e deseja obter, nesse domínio, um mínimo de apoio bibliográfico que lhe ofereça pistas de orientação.

A obra em apreço, devida aos cuidados de H. Solin (para os cognomes) e O. Salomies (para os gentilicios) não é um 'onomasticon' mas uma actualização do dicionário de Forcellini, do livro de I. Kajanto sobre os cognomes latinos (The Latin Cognomina, Helsínquia, 1965) e, sobretudo, do trabalho de W. Schulze \{Zur Geschichte Lateinischer Eigennamen, Berlim, 1966) sem as preocupações etimológicas deste último. Não inclui a onomástica de cariz regional, que para isso há os corpora específicos, de que são exemplo, para a Península Ibérica, os estudos de Untermann, Palomar Lapesa, Maria de Lourdes Albertos... Também não aborda a complexa problemática que preocupou, por exemplo, os investigadores presentes no colóquio 
sobre onomástica latina (L'OnomastiqueLatine, Actes du Colloque International sur l'Onomastique Latine organisé à Paris du 13 au 15 Octobre 1975, Paris, 1977) nem se debruça sobre as fases da aculturação onomástica nas várias partes do mundo romano apresentando mapas de distribuição de nomes.

É, pois, tão somente um repertorium voluntariamente assumido como actualização de Schulze e complemento a I. Kajanto (no que aos cognomes diz respeito). Com uma vantagem: a classificação em nomina (pp. 3-215) e cognomina (pp. 287-425) e — o que resulta de especial interesse para os epigrafistas — a sua enumeração por ordem alfabética das terminações (pp. 219-284: dos nomina', pp. 429473: dos cognomina). Na p. 474, breve suplemento.

Acompanhei de perto a iniciativa de André Mocsy, nos finais da década de 70, idêntica a esta mas baseada só no Corpus Inscriptionum Latinarum e seus aditamentos insertos na Ephemeris Epigraphica. O resultado foi o Nomenclator Provinciarum Europae Latinarum et Galliae Cisalpinae (Dissertationes Pannonicae, série III, 1, Budapeste, 1983) realizado com a colaboração de R. Feldmann, E. Marton e M. Sziláguyi, que vi anunciado e tentei obter, mas em vão. Trata-se, de facto, de um labor difícil, porque não há humanamente a possibilidade de sermos exaustivos e de se recolherem os antropónimos documentados nas epígrafes e nos textos literários. Uma obra assim, apesar de hoje muito facilitada do ponto de vista da concretização mercê da utilização da informática com programa adequado, requer importante trabalho de pesquisa, o compulsar sistemático dos índices do Année Épigraphique, dos corpora regionais publicados e - porque não ? - o cotejar das listas elaboradas com os dados informáticos de que vários centros de investigação em Epigrafia e em História Antiga já hoje largamente dispõem.

Neste aspecto - e cingindo-nos ao livro em apreço — teria sido interessante a apresentação da bibliografia compulsada. Acrescente-se, aliás, que somente epigrafistas bem adestrados nestas lides e, portanto, profundos conhecedores da bibliografia é que compreenderão integralmente e à primeira vista a totalidade das abreviaturas aí usadas. A obra reclamaria, assim, para a Epigrafia um carácter "elitista" com que inteiramente discordo. De resto, os autores parecem partir do princípio de que todos os historiadores possuem as citadas obras de W. Schulze e de I. Kajanto; constituem, de facto, trabalhos clássicos da onomástica, mas é natural que possam faltar nalguma biblioteca. Por conseguinte, a ausência duma tábua de abreviaturas com as indicações bibliográficas precisas parece-me importante lacuna que facilmente se teria podido preencher sem encarecer o volume nem fazer os seus autores roubarem muito tempo aos seus múltiplos afazeres. Pouparia, sim, muito tempo aos investigadores que nem sempre têm à mão as informações necessárias por mais ricas e bem apetrechadas que estejam as bibliotecas dos centros em que exercem a sua actividade.

A escassez do texto introdutório (três páginas) em Alemão justificaria também a sua síntese (ou mesmo tradução integral) numa língua mais acessível para os Ocidentais, que serão, afinal, os grandes utilizadores do Repertorium.

Aí se diz nomeadamente que a pesquisa terminou a 1 de Abril de 1987. Justificar-se-á, por isso, que Sagaius não figure entre os gentilicios pois, apesar de 
inserido em AE 1986 280, este volume da revista só foi posto à disposição dos utilizadores bastante depois daquela data. Mas fica-se, por exemplo, sem saber se Egitânia, de D. Fernando de Almeida (Lisboa, 1956), foi ou não consultada; se o próprio volume de José Vives, Inscripciones Latinas de la España Romana [=ILER] (Barcelona, 1971 e 1972) foi tido em consideração (Floricus, por exemplo, está aí documentado: n. ${ }^{\circ}$ 4512); se foi possível compulsar o meu trabalho, Inscrições Romanas do Conventus Pacensis (Coimbra, 1984).

Veja-se, a título de exemplificação, o caso de Oculatius a que já me referi no comentário a "Ficheiro Epigráfico" 163 (notas 5 e 6).

Além das ocorrências em 'ambiente' indígena peninsular, Oculatius é, num contexto claramente romanizado, mas ainda na Península Ibérica, o gentilicio duma família de burgueses municipais em Ibiza (CIL II3659 = ILER 364 e CIL II3662 = ILER 5530) e, na itálica Sarsina, um dos proeminentes membros da localmente bem notável gens Murcia ostenta Oculatius como cognome: L. Murcius A.f Pup. Oculatius: vide Alda CALBI, Sarsina: prosopografia e indici sociali, «Cultura Epigrafica dell'Appennino», Faenza, 1985, p. 166 n. ${ }^{\circ}$ 139. Kajanto, porém, não incluiu Oculatius entre os cognomes latinos; H. Solin e O. Salomies, ao invés, a propósito do monumento de Astorga onde a princípio se lera Oculasius como cognome de um Iulius (EE IX 292i) e provavelmente se deverá 1er de preferência este nome, incluem-no na lista dos cognomes, mas sob reservas (p. 371), certamente por desconhecerem o referido exemplo de Sarsina. Dúvidas destas seriam resolvidas com a apresentação de bibliografia.

As eventuais ausências de antropónimos não deslustrarão, no entanto, o trabalho, pois o grande mérito de Solin e Salomies reside precisamente no facto de nos terem facultado uma importante base de dados (aliás, o texto apresenta-se graficamente a partir da impressão por computador) que rapidamente será completada. Uma base de dados onomásticos sobejamente útil para ajudar na reconstituição de nomes de que, verbi gratia, só se percebem na pedra as terminações. Útil ainda porque - mesmo não tendo de imediato informações precisas — se fica a saber se determinado nome se encontra já documentado. Pode não se saber onde, mas sabe-se que existe e isso já é confortável.

Aliás, esse terá sido decerto primordialmente o objectivo dos autores - que, foi, portanto, conseguido em plenitude. Aos epigrafistas, no comentário à onomástica patente nos monumentos que estudarem, competirá enriquecer com outros dados estes que o Repertorium enumera.

É, pois, um vade-mecum indispensável.

JoSÉ D’EnCARNaÇão

La Langue des Inscriptions Latines de la Gaule, Collection du Centre d'Études Romaines et Gallo-Romaines, n. s., n. ${ }^{\circ}$ 7, Lyon, 1989, 172 pp., ilustr. ISBN: 2904974-06-7. 